\title{
Palliative sedation in Germany: factors and treatment practices associated with different sedation rate estimates in palliative and hospice care services
}

Stephanie Stiel ${ }^{1,2^{*}}$, Mareike Nurnus ${ }^{1}$, Christoph Ostgathe ${ }^{1}$ and Carsten Klein ${ }^{1}$

\begin{abstract}
Background: Clinical practice of Palliative Sedation (PS) varies between institutions worldwide and sometimes includes problematic practices. Little available research points at different definitions and frameworks which may contribute to uncertainty of healthcare professionals in the application of PS. This analysis investigates what demographic factors and characteristics of treatment practices differ between institutions with high versus low sedation rates estimates in Palliative and Hospice Care in Germany.
\end{abstract}

Methods: Data sets from 221 organisations from a prior online survey were separated into two sub-groups divided by their estimated sedation rate A) lower/equal to $16 \%(n=187 ; 90.8 \%)$ and B) higher than $16 \%(n=19 ; 9.2 \%)$ for secondary analysis. Demographic factors and characteristics of PS treatment practices between the two groups were compared using T-Tests and $\mathrm{Chi}^{2} /$ Fisher Exact Tests and considered significant ${ }^{*}$ ) at two-sided $p<.05$.

Results: Organisations in group B report that they discuss PS for a higher proportion of patients (38.5\%/10.2\%, $\left.p<0.000^{* *}\right)$, rate agitation more often as an indications for PS $\left(78.9 \% / 53.5 \%, p=0.050^{*}\right)$, and are more likely to use Lorazepam (63.2\%/37.4\%, $\left.p=0.047^{*}\right)$, Promethazin $\left(26.3 \% / 9.6 \%, p=0.044^{*}\right)$, and (Es-)Ketamin (31.6\%/ 12.8\%, $p=0.039^{*}$ ) than representatives in group A. Both groups differ significantly in their allocation of three case scenarios to different types of PS.

Conclusions: Both definitions and patterns of clinical practice between palliative and hospice care representatives show divergence, which may be influenced one by another. A comprehensive framework considering conceptual, clinical, ethical, and legal aspects of different definitions of PS could help to better distinguish between different types and nuances of PS.

Keywords: Palliative sedation, Framework, Standards, Drug monitoring, Symptom management, physician's practice patterns

\section{Background}

Despite holistic Palliative Care (PC) some patients experience unbearable suffering. Controlled 'Palliative sedation' (PS) can be an option for these patients [1]. PS has been defined as "the monitored use of medications intended to induce a state of decreased or absent awareness (unconsciousness) in order to relieve the burden of

\footnotetext{
* Correspondence: stiel.stephanie@mh-hannover.de

${ }^{1}$ Department of Palliative Medicine, University Hospital Erlangen,

Friedrich-Alexander-Universität Erlangen-Nürnberg, Erlangen, Germany

${ }^{2}$ Institute for General Practice, Hannover Medical School, Carl-Neuberg-Straße

1, 30625 Hannover, Germany
}

otherwise intractable suffering [...]" [2]. Hence uniformity on the understanding of PS is suggested by the definition, PS refers to a number of different practices which can vary in terms of intensity, time, and intended effects.

The (inter-)national evidence on indications [3], medications and dosages [4-6], and duration of PS in specialist palliative care (SPC) [7] is multifaceted. Studies concentrate on team attitudes [8], emotional burden [9] and experiences especially with continuous deep PS until the patient's death [10]. Several (inter-)national guidelines/ frameworks on PS have been published [11-13] including 
one from the European Association for Palliative Care (EAPC) [2]. However, the clinical practice still varies between institutions worldwide and so far no general clinical standard has been established.

A German questionnaire survey by the authors' working group confirmed numerous and substantial differences in the reported PS practices between different palliative and hospice care institutions [14, 15]. In this study, "the estimated frequency of PS ranges from 0 to $80 \%$ of all patients treated per year (mean 6.7\%) and some PC specialists report discussing PS as treatment option for every patient they encounter" [14]. The causes for these differences are not well explained yet.

Some of the differences may be due to problematic use of the measure. There is evidence that in single cases PS may be used (i) inappropriately and too hasty while neglecting multidimensional assessment and possible therapeutic options for patients [16], applying inadequate medications such as opioids for PS [17, 18], to alleviate staff members' burden [19] in decision-making for PS (ii) under delicate and sensitive indications such as requests for euthanasia [20], hence other therapeutic options than PS would be applicable [21], or due to family caregivers' wish for PS [16], or even (iii) abusively by physicians with the primary goal of hastening the patient's death $[22,23]$. All these problematic practices should be taken seriously to prevent mainly patients but also family caregivers and healthcare professionals from harm.

The available data addressing these clinical variations in PS already reveal a major challenge. The reported variation of sedation practices may be based at least partially on different understandings and definitions of PS which might be closely connected to a lack of widely accepted terminology and a consistent framework [24, 25]. These theoretical variations may result in uncertainty in the practical application of PS for healthcare professionals and might foster problematic practices.

To date there is a lack of comprehensive data and specific analyses that explain the substantially deviant sedation rates and differing treatment practices of PS in Germany.

\section{Study aim}

This secondary data analysis of a previous study from 2012, aimed to find and describe differences in clinical factors, ratings of case scenarios, and characteristics in institutions with high versus low sedation rates estimates in Palliative and Hospice Care in Germany. The findings will add to the discussion of different PS practices.

\section{Methods}

\section{Study material \& participants}

In 2012, an internally developed online questionnaire consisting of 34 questions divided into seven content sections (estimated number of patients, indications, monitoring, documentation, clinical practice, guidelines, and demographics) was sent out to 605 heads of palliative care units (PCU), hospices $(\mathrm{H})$, specialized palliative home care services for adults (SPHC), and specialized palliative home care services for children (SPPHC) listed in the German official address registers. They were asked to give information about their organisations' usual clinical practice of PS reflecting a period of 1 year [14].

The initial survey included seven written case scenarios displaying different patterns of PS which were rated by the organisations as PS ("yes"), no PS ("no") or undecided ("unsure") (for original scenario description see Table 2). The case scenario descriptions were constructed in order to cover the different forms of PS [26].These cases were intended to better understand the individual definition of PS the clinicians work with.

A) Symptom oriented treatment resulting in sedation, may also be PS to alleviate otherwise intractable suffering (symptom: agitation)

B) Symptom oriented treatment resulting in sedation (symptom: delirium)

C) Symptom oriented treatment resulting in sedation (symptom: pain due to muscle cramps)

D) secondary sedative effect of other medication not primarily intended for PS (symptom: pain)

E) PS to alleviate otherwise intractable suffering (symptom: nausea)

F) PS in the dying phase due to an acute event (symptom: bleeding)

G) intermittent PS for symptom relief (symptom: existential suffering)

Overall, 225 questionnaires were returned resulting in a response rate of $37.2 \%$ of all invited representatives. Four data sets had to be excluded due to inconsistencies, so that $n=221$ data sets were considered for further analysis. The overall frequency of the use of PS reported by these 221 participating organisations varied from 0 to 80\% (mean 6.7\%; SD $\pm 9.3 \%$; median 3.8\%; $n=206 ; n=15$ missing values [14].

\section{Statistical analysis}

IBM SPSS Statistics 21 (SPSS Inc., Chicago, IL, USA) for Windows was used for statistical analysis.

For the analysis at hand, first, all data sets were allocated to two sub-groups divided by their estimated low versus high sedation rate. This sub-group classification is based on statistical suggestions regarding the actual empirical data distribution from the former survey study. The cut-off point was set to the sum of the mean value (6.7\%) plus one SD (9.3\%) to contrast the most striking outlier data of organisations' estimated PS prevalence effectively [14]. The two established groups are A) estimated 
sedation rate is lower /equal to $16 \%$ ( $n=187$ organisations; $90.8 \%)$ and B) estimated sedation rate is higher than $16 \%$ ( $n=19$ organisations; $9.2 \%$ ). Descriptive data (mean, median, standard deviation (SD), range from minimum to maximum) for the description of the characteristics of the total sample and the two sub-groups as well as treatment practices were calculated.

Second, to compare demographic factors, characteristics of treatment practices, and ratings of seven case scenarios (see Table 2) between these two groups T-Tests were performed in variables with interval or ratio scales, $\mathrm{Chi}^{2} /$ Fisher Exact Tests in variables with nominal or ordinal scales. All tests were considered significant $(*)$ at two-sided $p<.05$.

\section{Ethics}

The study plan was presented to the ethics committee of the medical faculty of Erlangen. A formal approval was not regarded to be necessary.

\section{Results}

What are the differences in treatment practices between participating organisations with high versus low sedation rate estimates?

Organisations in group B (high estimated sedation rate) reported that

i) they discussed PS as an option for therapy in a significantly higher proportion of patients $(38.5 \%$ versus $\left.10.2 \%, p<0.000^{* * *}\right)$,

ii) the rate of agitation as one of the four most frequent indications for PS was significantly higher $(78.9 \%$ versus $53.5 \%, p=0.050 \%$,

iii) they evaluate symptoms during PS significantly less often (never: $5.6 \%$ versus $0 \%$; sometimes: $0 \%$ versus $2.8 \%$; mostly: $11.1 \%$ versus $8.5 \%$; always: $83.3 \%$ versus $\left.88.7 \%, p<0.015^{*}\right)$,

iv) they were significantly more likely to use Lorazepam $\left(=\right.$ Tavor $\left.^{\oplus}\right)\left(63.2 \%\right.$ versus $\left.37.4 \%, p=0.047^{*}\right)$, Promethazin $\left(=\right.$ Atosil $\left.^{\odot}\right)(26.3 \%$ versus $9.6 \%, p=0.044 \%)$, and (Es-)Ketamin $\left(=\right.$ Ketanest $\left.^{\circ}\right)(31.6 \%$ versus $12.8 \%$, $\left.p=0.039^{*}\right)$,

v) they planned significantly different time intervals until weaning phases during PS ( $<12 \mathrm{~h}$ : $41.7 \%$ versus $13.3 \%$; $12-24$ h: $25.0 \%$ versus $61.1 \%$; $>24$ h: $33.3 \%$ versus $25.7 \%, p=0.017 *$ )

than representatives of organisations in group A (low estimated sedation rate) (see Table 1).

What are the differences in the ratings of case scenarios (see Table 2) between participating organisations with high versus low sedation rate estimates? Organisations in group B (high sedation rate) i) rated scenario $\mathrm{D}$ (representing secondary sedative effect of other medication not primarily intended for PS) significantly more often as PS (29.4\% versus $8.5 \%$, $\left.p=0.025^{*}\right)$,

ii) rated scenario $\mathrm{F}$ (representing PS in the dying phase due to an acute event) significantly more often as PS (100\% versus $\left.64.2 \%, p=0.011^{*}\right)$,

iii) rated scenario $G$ (representing intermittent PS for symptom relief) significantly less often as PS (70.6\% versus $79.6 \%, p=0.042^{*}$ )

than representatives of organisations in group A (low sedation rate) (see Table 2).

\section{Differences in demographic staff data between organisations with low versus high sedation rate estimates}

The percentage of physicians specialised in internal medicine was by trend higher in group A with a low sedation rate estimate ( $32.4 \%$ versus $10.5 \%, p=0.64)$. The percentage of physicians specialised in anaesthesiology, neurology, general medicine, and radiotherapy was equally distributed in both groups $(p>0.237)$.

Neither group differed in terms of sex, age, professional group, years of professional experience and years of professional experience in palliative and hospice care $(p>0.085)$. No significant differences were found in the distribution of palliative and hospice care settings within both groups, the proportion of representatives from inpatient hospices, paediatric and adult community palliative care teams, and the proportion of inpatient and outpatient care setting representatives $(p>0.338)$.

\section{Discussion}

The study at hand aimed at identifying possible factors of palliative and hospice care representatives and characteristics of treatment practices associated with differences between certain institutions that estimated a high versus low sedation rate in their service in a survey on PS in Germany.

The starting point and findings reported here show that there were considerable differences between palliative and hospice care services first in their sedation rate estimates, second in their clinical PS practices and third in their definitions of different PS practices.

The estimated prevalence of PS found in our questionnaire study [14] has been confirmed by data of other studies in Germany. Three papers report prevalence rates between 7 and 34\% [3, 27, 28]. Compared to German findings, an international review by Maltoni et al., however, found an even higher range between sedation rates from $14.6 \%$ to $66.7 \%$ among 1.807 consecutive patients from 10 different studies [29]. Different clinical practices of PS in palliative and hospice care in Germany resulting from the presented analysis affect in particular indications for PS, 
Table 1 Differences of ratings between Group A and Group B to online survey on Palliative Sedation calculated by ${ }^{\mathrm{a}} \mathrm{T}$-Test; ${ }^{\mathrm{b}}$ Fisher Exact Test; ${ }^{C} \mathrm{Chi}^{2}$ test (all considered significant at $p<0.05^{*}$ )

\begin{tabular}{|c|c|c|c|c|c|}
\hline Questionnaire section & Item & \multicolumn{2}{|c|}{$\begin{array}{l}\text { Group A: low sedation } \\
\text { rate estimates }(n)\end{array}$} & $\begin{array}{l}\text { Group B: high sedation } \\
\text { rate estimates }(n)\end{array}$ & $p$ \\
\hline \multirow[t]{2}{*}{1 Prevalence } & aPS discussed as an option for therapy & \multicolumn{2}{|c|}{$10.20 \% \pm 9.41 \%(183)$} & $38.49 \% \pm 22.08 \%(19)$ & $0.000^{* *}$ \\
\hline & 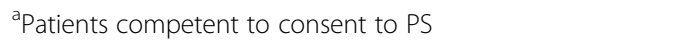 & \multicolumn{2}{|c|}{$51.65 \% \pm 37.78 \%(183)$} & $52.58 \% \pm 28.57 \%(19)$ & 0.917 \\
\hline \multirow[t]{2}{*}{2 Indications } & ${ }^{\mathrm{b}}$ Agitation & \multicolumn{2}{|c|}{$53.5 \%$} & $78.9 \%$ & $0.050^{*}$ \\
\hline & \multicolumn{4}{|c|}{ 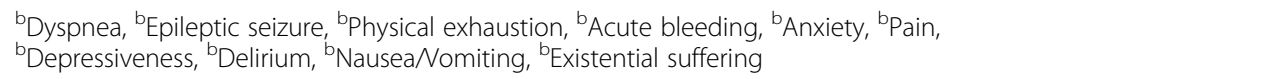 } & $>0.143$ \\
\hline \multirow[t]{13}{*}{3 Evaluation } & \multirow[t]{4}{*}{${ }^{c}$ Evaluation of level of consciousness during PS $(n=179 / 18)$} & Never & $2.2 \%$ & $5.6 \%$ & \multirow[t]{4}{*}{$>0.570$} \\
\hline & & Sometimes & $5.0 \%$ & $11.1 \%$ & \\
\hline & & Mostly & $21.2 \%$ & $16.7 \%$ & \\
\hline & & Always & $71.6 \%$ & $66.6 \%$ & \\
\hline & \multirow[t]{4}{*}{${ }^{c}$ Evaluation of symptoms during PS $(n=177 / 18)$} & Never & $0.0 \%$ & $5.6 \%$ & \multirow[t]{4}{*}{$0.015^{*}$} \\
\hline & & Sometimes & $2.8 \%$ & $0.0 \%$ & \\
\hline & & Mostly & $8.5 \%$ & $11.1 \%$ & \\
\hline & & Always & $88.7 \%$ & $83.3 \%$ & \\
\hline & \multicolumn{4}{|c|}{$\begin{array}{l}\text { bWay of evaluating depth of sedation (monitoring, response, touching, pain stimulus, } \\
\text { appraisal of vital signs, dose rate of drugs, response of close ones) }\end{array}$} & $>0.079$ \\
\hline & \multicolumn{4}{|l|}{ 'How often level of consciousness/symptoms are evaluated } & 0.509 \\
\hline & \multicolumn{4}{|l|}{ "Who conducts evaluation } & 0.882 \\
\hline & \multicolumn{4}{|c|}{$\begin{array}{l}\text { bUse of scores for evaluation of level of consciousness (Richmond-Agitation-Sedation-Score, } \\
\text { Ramsay-Sedation-Score, Agitation Distress Scale) }\end{array}$} & $>0.208$ \\
\hline & \multicolumn{4}{|c|}{$\begin{array}{l}\text { bUse of scores for evaluation of level of symptoms (VAS/NRSNRS, Edmonton Symptom } \\
\text { Assessment System, Minimal Documentation System, symptom and problem checklist from HOPE) }\end{array}$} & $>0.228$ \\
\hline \multirow[t]{4}{*}{4 Documentation } & \multicolumn{4}{|l|}{ Areas of documentation before sedation } & $>0.122$ \\
\hline & \multicolumn{4}{|c|}{ 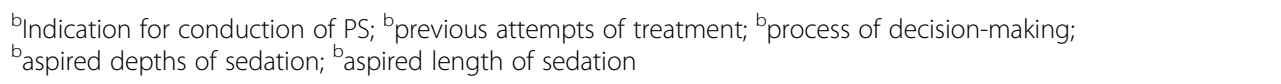 } & \\
\hline & \multicolumn{4}{|c|}{ Area of documentation during sedation: } & $>0.233$ \\
\hline & \multicolumn{4}{|c|}{$\begin{array}{l}\text { bdrugs, dosage and application method; }{ }^{b} \text { vital signs; }{ }^{b} \text { transmitting of alimentation/liquids; } \\
\text { bother drugs/medical measures }\end{array}$} & \\
\hline \multirow[t]{12}{*}{5 Treatment Strategies } & \multicolumn{4}{|l|}{ Drugs used for PS (187/19): } & \\
\hline & \multicolumn{2}{|l|}{ bLorazepam (=Tavor $\left.{ }^{\oplus}\right)$} & $37.4 \%$ & $63.2 \%$ & $0.047^{*}$ \\
\hline & \multicolumn{2}{|l|}{${ }^{\text {b}}$ Promethazin $\left(=\right.$ Atosi $\left.{ }^{\oplus}\right)$} & $9.6 \%$ & $26.3 \%$ & $0.044^{*}$ \\
\hline & \multicolumn{2}{|l|}{${ }^{\mathrm{b}}\left(\right.$ Es-)Ketamin $\left(=\right.$ Ketanest $\left.^{\oplus}\right)$} & $12.8 \%$ & $31.6 \%$ & $0.039^{*}$ \\
\hline & \multicolumn{4}{|c|}{ 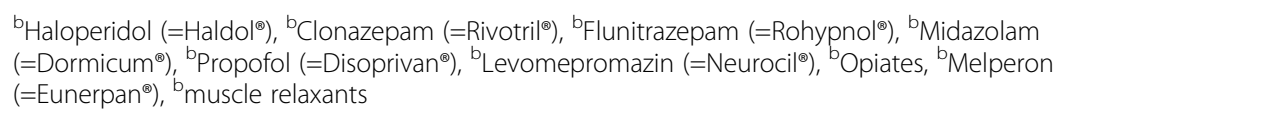 } & $>0.128$ \\
\hline & Way of regulating of level of consciousness & & & & $>0.554$ \\
\hline & ${ }^{\mathrm{C}}$ Aiming for weaning phases after what length of sedation (1 & 3/12): & & & \\
\hline & $<12 \mathrm{~h}$ & & $13.3 \%$ & $41.7 \%$ & $0.017^{*}$ \\
\hline & $12-24 \mathrm{~h}$ & & $61.0 \%$ & $25.0 \%$ & \\
\hline & $>24 \mathrm{~h}$ & & $25.7 \%$ & $33.3 \%$ & \\
\hline & Artificial hydration/nutrition: & & & & $>0.763$ \\
\hline & $\begin{array}{l}{ }^{C} \text { Patients competent to consent to therapy decide on artificic } \\
{ }^{C} \text { Independent from decision PS; }{ }^{C} \text { Belongs to basic supply; }{ }^{C} \mathrm{~W}\end{array}$ & $\begin{array}{l}\text { hydration/nut } \\
\text { thhold }\end{array}$ & tion; & & \\
\hline 6 Guidelines & 'Internal guidelines/instructions for PS available & & & & $>0.855$ \\
\hline & ${ }^{\text {b} K n o w l e d g e ~ o f ~(i n t e r-) n a t i o n a l ~ g u i d e l i n e s ~}$ & & & & $>0.624$ \\
\hline & ${ }^{c}$ Extent of consideration of guidelines & & & & $>0.539$ \\
\hline
\end{tabular}


Table 2 Differences in the distribution of percentages (\%) of answers of Group A and Group B to case scenarios (Chi ${ }^{2}$ Test; $p<0.05$ considered significant ${ }^{*}$ )

\begin{tabular}{|c|c|c|c|c|}
\hline 7) Definition: Case scenario & Rating & Group A & Group B & $p$ \\
\hline \multirow{4}{*}{$\begin{array}{l}\text { [A] To relief a patients agitation through clouded awareness he receives over } 24 \mathrm{~h} \\
48 \mathrm{mg} \text { Midazolam (=Dormicum }{ }^{\oplus} \text { ) through a syringe driver. During this treatment, } \\
\text { which is continued right up to his death, it is impossible to carry on a conversation } \\
\text { with him. }\end{array}$} & no & $14.3 \%$ & $17.7 \%$ & \multirow[t]{4}{*}{.536} \\
\hline & yes & $66.1 \%$ & $52.9 \%$ & \\
\hline & unsure & $19.6 \%$ & $29.4 \%$ & \\
\hline & & $(n=168)$ & $(n=17)$ & \\
\hline \multirow{4}{*}{$\begin{array}{l}\text { [B] A delirious patient is treated with } 2 \mathrm{mg} \text { Haloperidol }\left(=\mathrm{Haldo}^{\circledast}\right) \text { for every } 6 \mathrm{~h} \text {. } \\
\text { Under this dosage, which is necessary for a successful treatment, he seems obviously } \\
\text { sedated. }\end{array}$} & no & $84.4 \%$ & $76.5 \%$ & \multirow[t]{4}{*}{.660} \\
\hline & yes & $6.6 \%$ & $11.8 \%$ & \\
\hline & unsure & $9.0 \%$ & $11.7 \%$ & \\
\hline & & $(n=167)$ & $(n=17)$ & \\
\hline \multirow{4}{*}{$\begin{array}{l}\text { [C] Under the medical indication of pronounced muscle cramps a patient receives } \\
\text { circadian } 10 \text { mg Diazepam (=Valium }{ }^{\oplus} \text { ) daily. Symptoms are soothed through the } \\
\text { consequential sedation. Medication is continued for several days and nights. Despite } \\
\text { somnolence, patient can welcome and greet visitors, until he finally passes away. }\end{array}$} & no & $73.6 \%$ & $64.7 \%$ & \multirow[t]{4}{*}{.703} \\
\hline & yes & $16.2 \%$ & $23.5 \%$ & \\
\hline & unsure & $10.2 \%$ & $11.8 \%$ & \\
\hline & & $(n=167)$ & $(n=17)$ & \\
\hline \multirow{4}{*}{$\begin{array}{l}\text { [D] A patient suffering from intense pain needs a daily dose of } 300 \mathrm{mg} \text { Morphium s.c.. } \\
\text { Under this medication he appears exceedingly somnolent and sedated, but can be } \\
\text { awakened through loud address. }\end{array}$} & no & $80.0 \%$ & $64.7 \%$ & \multirow[t]{4}{*}{$.025^{*}$} \\
\hline & yes & $8.5 \%$ & $29.4 \%$ & \\
\hline & unsure & $11.5 \%$ & $5.9 \%$ & \\
\hline & & $(n=165)$ & $(n=17)$ & \\
\hline \multirow{4}{*}{$\begin{array}{l}\text { [E] Because of not otherwise manageable nausea the patient is treated with } 2.5 \mathrm{mg} \\
\text { Lorazepam (=Tavor }{ }^{\oplus} \text { every } 8 \mathrm{~h} \text {. Under this therapy patient is sleeping. During two } \\
\text { attempts of reducing the dose he declares that the nausea persists. Therefore } \\
\text { medication is increased again. Few hours after adjustment of dose he passes away. }\end{array}$} & no & $36.6 \%$ & $29.4 \%$ & \multirow[t]{4}{*}{.733} \\
\hline & yes & $48.8 \%$ & $58.8 \%$ & \\
\hline & unsure & $14.6 \%$ & $11.8 \%$ & \\
\hline & & $(n=164)$ & $(n=17)$ & \\
\hline \multirow{4}{*}{$\begin{array}{l}\text { [F] Due to dinstinctive and severe life-threatening tumour haemorrhage and the } \\
\left.\text { fulminant panic attack a patient receive } 10 \mathrm{mg} \text { Midazolam (=Dormicum }{ }^{\oplus}\right) \text { i.v. }\end{array}$} & no & $23.5 \%$ & $0.0 \%$ & \multirow[t]{4}{*}{$.011^{*}$} \\
\hline & yes & $64.2 \%$ & $100.0 \%$ & \\
\hline & unsure & $12.3 \%$ & $0.0 \%$ & \\
\hline & & $(n=162)$ & $(n=17)$ & \\
\hline \multirow{4}{*}{$\begin{array}{l}\text { [G] According to the wish of a patient she receives under indication of existential } \\
\text { suffering } 3 \mathrm{mg} / \mathrm{h} \text { Midazolam (=Dormicum }{ }^{\circledast} \text {. To determine patients wish again, } \\
\text { dose is reduced after } 24 \mathrm{~h} \text {. As patient does not want a continuation of medication } \\
\text { it is weaned. }\end{array}$} & no & $10.5 \%$ & $29.4 \%$ & \multirow[t]{4}{*}{$.042^{*}$} \\
\hline & yes & $79.6 \%$ & $70.6 \%$ & \\
\hline & unsure & $9.9 \%$ & $0.0 \%$ & \\
\hline & & $(n=162)$ & $(n=17)$ & \\
\hline
\end{tabular}

* and bold numbers are with significance

frequency of symptom evaluation during PS, the usage of drugs, and planned weaning phases during PS in this analysis. These deviations are also reflected in and in accordance with the current international research literature which reports a wide range of indications for PS [4, 29], different medications and dosages [5, 6], and patterns of evaluation and monitoring PS [30]. The divergence in clinical practice seems to be associated with different understandings of PS [31-33]. Several authors already pointed at a lack of accepted terminology and a consistent framework which makes it difficult to describe different PS practices [25, 34]. Even different frameworks that should assist as guidance vary considerably in content and quality [35]. The parent study to this analysis [14] showed that a considerable percentage of institutional representatives were not aware of the EAPC framework [2] or its German translation [36].

Our analysis supports the notion that palliative and hospice care professionals do not agree on a clear definition of PS versus a loose collective term for numerous nuances and types of PS. The case scenarios were assigned to varying definitions of PS and the assignment seem to have an impact on the estimated sedation rat in the service. This raises the questions whether due to these multi-layered and broad variances, palliative and hospice care practitioners may experience uncertainty in clinical PS practice. In consequence, the preparation, discussion, and decision making prior to PS, the evaluation and documentation of PS and the assessment of PS outcomes are set into practice very differently $[14,15]$. In particular misunderstandings on definition of PS may foster problematic practices, which should be prevented. 
This study shows no clear signs of associations between health care professionals' demographic data and profession-related background on the one hand and their PS practice of high versus low sedation rate on the other.

\section{Study limitations}

The results of the study are somewhat limited by a rather low response rate to the questionnaire of the main study, a lack of information about possible non-response bias and by an unequal percentage of representatives from all palliative and hospice care settings. These limitations may constrain the generalizability of the data.

Furthermore, answers to the questionnaire may include estimation errors. This uncertainty about the extent to which the views of the interviewees are representative of the population of German palliative medicine specialists is compounded by the uncertainty about the extent to which the responses reflect actual care delivery.

The rationale for determining the cut point distinguishing low vs. high estimated PS rates is based on statistical suggestions regarding the data distribution from the former survey study. The cut-off point was set to the sum of the mean value (6.7\%) plus one SD (9.3\%) to contrast effectively the striking outlier data. To our knowledge no workgroup or publication has yet defined a reasonable cut point for low vs. high estimated PS rates and data on PS prevalence differ considerably, so that this is a whole new approach to extend evidence. This rationale and missing comparable approaches challenge the interpretation of the group comparisons, as does the inability to perform multivariable analysis. Nonetheless, differences in treatment practice are tangible, but cannot allow statistical inference for the entire population of German PC institutions.

From a methodological point of view, the number of data sets in each group (A versus B) was distributed unequally. A certain bias may derive from the allocation of the low and high sedation rate groups, because the cutoff was set considering clinical, empirical and scientific arguments.

\section{Conclusions}

The analysis presented here gives new impetus to describing clinical differences in PS practice and imbedding them in a broader context. Both definitions and patterns of clinical practice between palliative and hospice care representatives show divergence, which may be closely interrelated and mutually dependent.

More research is needed (i) to describe existing differences in definitions and clinical patterns of PS between care practitioners, in order to (ii) better explain the investigated divergence and the relation between certain aspects of PS. A comprehensive practical framework considering conceptual, clinical, ethical, and legal aspects of different definitions of PS could help to better distinguish between different types and nuances of PS.

This may help in long-term to minimise problematic practice and prevent patients, family caregivers and healthcare professionals from harm.

\section{Abbreviations}

EAPC: European Association for Palliative Care; H: Hospices; PC: Palliative care: PCU: Palliative care units; PS: Palliative sedation; SD: Standard deviation;

SPHC: Specialized palliative home care services for adults; SPPHC: Specialized palliative home care services for children

\section{Acknowledgements}

We thank all participating organisations for answering the questionnaire survey.

\section{Funding}

This study received no grant.

\section{Availability of data and materials}

The datasets used and/or analysed during the current study available from the corresponding author on reasonable request.

\section{Authors' contributions}

SS developed and applied the questionnaire survey, carried out the study statistics, wrote the manuscript, and manged the manuscript revision. MN participated in the performance of the statistical analysis and developed tables in the manuscript. CO participated in the design of the study. CK developed and applied the questionnaire survey, participated in the design of the study, and helped to draft the manuscript. All authors read and approved the final manuscript.

\section{Ethics approval and consent to participate}

The study plan was presented to the ethics committee of the medical faculty of Erlangen. A formal approval was not regarded to be necessary, because no patients were involved in this investigation.

\section{Consent for publication}

Not applicable.

\section{Competing interests}

The authors declare that they have no competing interests.

\section{Publisher's Note}

Springer Nature remains neutral with regard to jurisdictional claims in published maps and institutional affiliations.

Received: 16 January 2017 Accepted: 5 March 2018

Published online: 13 March 2018

\section{References}

1. Mercadante S, Intravaia G, Villari P, Ferrera P, David F, Casuccio A. Controlled sedation for refractory symptoms in dying patients. J Pain Symptom Manag. 2009;37(5):771-9.

2. Cherny NI, Radbruch L, Board of the European Association for Palliative C. European Association for Palliative Care (EAPC) recommended framework for the use of sedation in palliative care. Palliat Med. 2009;23(7):581-93.

3. Muller-Busch HC, Andres I, Jehser T. Sedation in palliative care - a critical analysis of 7 years experience. BMC Palliat Care. 2003;2(1):2.

4. Van Deijck RH, Krijnsen PJ, Hasselaar JG, Verhagen SC, Vissers KC, Koopmans RT. The practice of continuous palliative sedation in elderly patients: a nationwide explorative study among Dutch nursing home physicians. J Am Geriatr Soc. 2010;58(9):1671-8.

5. Carter MJ, Gibbins J, Senior-Smith G, Thomas S, Guest P, Forbes K. Ketamine: does it have a role in palliative sedation? J Pain Symptom Manag. 2008;36(4):e1-3.

6. Oosten AW, Oldenmenger WH, van Zuylen C, Schmitz Pl, Bannink M, Lieverse PJ, Bromberg JE, van der Rijt CC. Higher doses of opioids in 
patients who need palliative sedation prior to death: cause or consequence? Eur J Cancer. 2011;47(15):2341-6.

7. Stiel S, Krumm N, Schroers O, Radbruch L, Elsner F. Indications and use of benzodiazepines in a palliative care unit. Schmerz. 2008;22(6):665-71.

8. Morita T, Akechi T, Sugawara Y, Chihara S, Uchitomi Y. Practices and attitudes of Japanese oncologists and palliative care physicians concerning terminal sedation: a nationwide survey. J Clin Oncol. 2002;20(3):758-64.

9. Morita T, Miyashita M, Kimura R, Adachi I, Shima Y. Emotional burden of nurses in palliative sedation therapy. Palliat Med. 2004;18(6):550-7.

10. Swart SJ, Brinkkemper T, Rietjens JA, Blanker MH, van Zuylen L, Ribbe M, Zuurmond WW, van der Heide A, Perez RS. Physicians' and nurses' experiences with continuous palliative sedation in the Netherlands. Arch Intern Med. 2010;170(14):1271-4.

11. Braun TC, Hagen NA, Clark T. Development of a clinical practice guideline for palliative sedation. J Palliat Med. 2003;6(3):345-50.

12. Morita T, Bito S, Kurihara Y, Uchitomi Y. Development of a clinical guideline for palliative sedation therapy using the Delphi method. J Palliat Med. 2005;8(4):716-29.

13. Verkerk M, van Wijlick E, Legemaate J, de Graeff A. A national guideline for palliative sedation in the Netherlands. J Pain Symptom Manag. 2007;34(6):666-70.

14. Klosa PR, Klein C, Heckel M, Bronnhuber AC, Ostgathe C, Stiel S. The EAPC framework on palliative sedation and clinical practice-a questionnaire-based survey in Germany. Support Care Cancer. 2014:22(10):2621-8.

15. Stiel S, Heckel M, Christensen B, Ostgathe C, Klein C. In-service documentation tools and statements on palliative sedation in Germany-do they meet the EAPC framework recommendations? A qualitative document analysis. Support Care Cancer. 2016;24(1):459-67.

16. Higgins PC, Altilio T. Palliative sedation: an essential place for clinical excellence. J Soc Work End Life Palliat Care. 2007;3(4):3-30.

17. Hasselaar JG, Reuzel RP, Verhagen SC, de Graeff A, Vissers KC, Crul BJ. Improving prescription in palliative sedation: compliance with dutch guidelines. Arch Intern Med. 2007;167(11):1166-71.

18. Reuzel RP, Hasselaar GJ, Vissers KC, van der Wilt GJ, Groenewoud JM, Crul BJ. Inappropriateness of using opioids for end-stage palliative sedation: a Dutch study. Palliat Med. 2008;22(5):641-6.

19. Rietjens JA, Hauser J, van der Heide A, Emanuel L. Having a difficult time leaving: experiences and attitudes of nurses with palliative sedation. Palliat Med. 2007;21(7):643-9.

20. Hasselaar JG, Reuzel RP, van den Muijsenbergh ME, Koopmans RT, Leget CJ, Crul BJ, Vissers KC. Dealing with delicate issues in continuous deep sedation. Varying practices among Dutch medical specialists, general practitioners, and nursing home physicians. Arch Intern Med. 2008;168(5):537-43.

21. Fainsinger RL, De Moissac D, Mancini I, Oneschuk D. Sedation for delirium and other symptoms in terminally ill patients in Edmonton. J Palliat Care. 2000;16(2):5-10.

22. Douglas $C D$, Kerridge $I H$, Rainbird KJ, McPhee JR, Hancock L, Spigelman AD. The intention to hasten death: a survey of attitudes and practices of surgeons in Australia. Med J Aust. 2001;175(10):511-5.

23. Weber M, Strohscheer I, Samonigg H, Huber C. Palliative sedation-an alternative to euthanasia in intractable pain at the end of life? Med Klin (Munich). 2005;100(5):292-8.

24. Alt-Epping B, Nauck F, Jaspers B. What is problematic with palliative sedation?: a review. Ethik in der Medizin. 2014;27(3):219-31.

25. Bozzaro C. The concept of suffering in medicine: an investigation using the example of deep palliative sedation at the end of life. Ethik in der Medizin. 2015;27(2):93-106

26. Morita T, Tsuneto S, Shima Y. Proposed definitions for terminal sedation. Lancet. 2001;358(9278):335-6.

27. Jaspers B, Nauck F, Lindena G, Elsner F, Ostgathe C, Radbruch L. Palliative sedation in Germany: how much do we know? A prospective survey. J Palliat Med. 2012;15(6):672-80.

28. Hopprich A, Gunther LD, Laufenberg-Feldmann R, Reinholz U, Weber M. Palliative sedation at a university palliative care unit-a descriptive analysis. Dtsch Med Wochenschr. 2016;141(8):e60-6.

29. Maltoni M, Scarpi E, Rosati M, Derni S, Fabbri L, Martini F, Amadori D, Nanni O. Palliative sedation in end-of-life care and survival: a systematic review. J Clin Oncol. 2012;30(12):1378-83.

30. Brinkkemper T, van Norel AM, Szadek KM, Loer SA, Zuurmond WW, Perez RS. The use of observational scales to monitor symptom control and depth of sedation in patients requiring palliative sedation: a systematic review. Palliat Med. 2013;27(1):54-67.
31. Schildmann EK, Bausewein C, Schildmann J. Palliative sedation: improvement of guidelines necessary, but not sufficient. Palliat Med. 2015;29(5):479-80.

32. Beel $\mathrm{A}, \mathrm{McClement} \mathrm{SE}$, Harlos M. Palliative sedation therapy: a review of definitions and usage. Int J Palliat Nurs. 2002;8(4):190-9.

33. Morita T, Tsuneto S, Shima Y. Definition of sedation for symptom relief: a systematic literature review and a proposal of operational criteria. J Pain Symptom Manag. 2002;24(4):447-53.

34. Alt-Epping B, Nauck F, Jaspers B. What is problematic with palliative sedation? A review. Ethik in der Medizin. 2015;27(3):2019-31.

35. Schildmann EK, Schildmann J, Kiesewetter I. Medication and monitoring in palliative sedation therapy: a systematic review and quality assessment of published guidelines. J Pain Symptom Manag. 2015;49(4):734-46.

36. Alt-Epping B, Sitte T, Nauck F, Radbruch L. Sedation in palliative medicine: guidelines for the use of sedation in palliative care: European Association for Palliative Care (EAPC). Schmerz. 2010;24(4):342-54.

\section{Submit your next manuscript to BioMed Central and we will help you at every step:}

- We accept pre-submission inquiries

- Our selector tool helps you to find the most relevant journal

- We provide round the clock customer support

- Convenient online submission

- Thorough peer review

- Inclusion in PubMed and all major indexing services

- Maximum visibility for your research

Submit your manuscript at www.biomedcentral.com/submit
) Biomed Central 